Romanenko I. Yu. Characteristics of Anxiety Manifestations and Hormonal Profile of Women with Threatened Interruption of Pregnancy, Living in Lugansk Region. Journal of Education, Health and Sport. 2020;10(10):237-244. eISSN 2391-8306. DOI http://dx.doi.org/10.12775/JEHS.2020.10.10.022

https://apcz.umk.pl/czasopisma/index.php/JEHS/article/view/JEHS.2020.10.10.022

https://zenodo.org/record/4394360

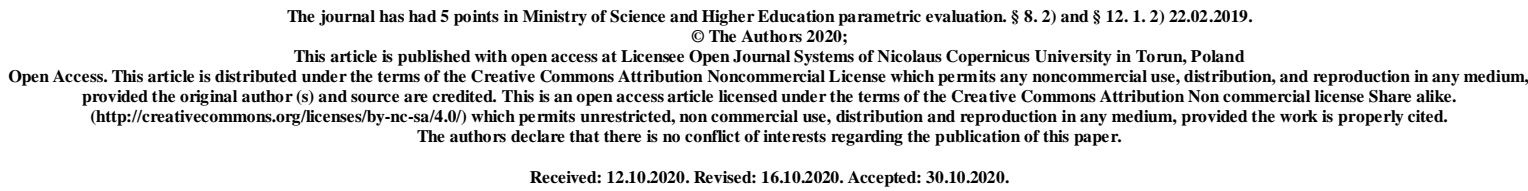

UDC 618.39-036.3/.4:616.89-008.19-07:[612.621.31:612.43.018]- 055.2"364"(477.61)

\title{
Characteristics of Anxiety Manifestations and Hormonal Profile of Women with Threatened Interruption of Pregnancy, Living in Lugansk Region
}

\section{Yu. Romanenko}

\section{Ukrainian Scientific and Practical Center for Endocrine Surgery, Transplantation of Endocrine Organs and Tissues of the Ministry of Health of Ukraine, Kyiv, Ukraine}

\section{Abstract}

The threatened interruption of pregnancy (TIP) is the most common pregnancy complication that occurs in $15-20 \%$ of cases of ongoing pregnancy. The aim of the study was to identify the prevalence and severity of anxiety, the hormonal profile of in pregnant women with threatened interruption of pregnancy in the I and II trimesters, living in the Lugansk region in the area of armed conflict in Eastern Ukraine, to improve treatment and prophylactic measures and prevent obstetric and perinatal complications in such women. Material and methods. The study included 67 pregnant women who were hospitalized regarding TIP to the hospitals, located in the Lugansk region (group I). The control group consisted of 30 pregnant women with non-complicated obstetric anamnesis and physiological course of pregnancy with similar gestational period of pregnancy and place of residence (group II). Spielberger State-Trait Anxiety Inventory was used to assess the level of anxiety, quantitative assessment of concentration of estradiol, progesterone, prolactin, cortisol in blood plasma was determined. Results and discussion. Prevalence of anxiety disorders among pregnant women with TIP living in the armed conflict area was in 2.4 times more often than 
healthy pregnant women and made up $68,60 \%$. They have significantly higher levels of state and trait anxiety; a positive correlation between the level of state anxiety and concentrations of cortisol, prolactin were found. Conclusions. Antenatal study of levels of anxiety, hormonal homeostasis in pregnant women with TIP living in the armed conflict area allowed to individualize the approach to the management of pregnancy and if needed to timely develop rehabilitating activities, that will contribute to a successful outcome of the pregnancy and affect the health of the mother and her offspring.

Keywords: pregnancy; threatened interruption of pregnancy; progesterone; prolactin; cortisol; anxiety.

Background. Pregnant women are very susceptible to various environmental influences. During pregnancy, mental well-being is expressed in the ability of the expectant mother to adequately show her behavior, regulate her mental state, adapting to the conditions of a crisis situation [1]. The protracted armed conflicts create not only political, legal, socioeconomic problems, form the migration flows of the population, but also affect the somatic and mental health of people. Women involved in armed conflict are often influenced by traumatic events and daily stresses with a risk of increased levels of mental disorders; Pregnancy itself is a critical stage in the development of a woman's personality. Chronic stress can affect the course of pregnancy, leading to an increase in the number of complications. During and after emergencies, people begin to face various mental health problems. Some of them have additional mental disorders, while others experience psychological distress [2 - 5].

Research results of A.M. Lee et al. showed that about $54 \%$ of women experience anxiety throughout their pregnancy

The threatened interruption of pregnancy (TIP) is the most common pregnancy complication that occurs in $15-20 \%$ of cases of ongoing pregnancy. TIP has associated with preterm labor and low birth weight, pre-eclampsia, preterm prelabour rupture of membranes, placental abruption and intrauterine growth restriction [9]. The problem of miscarriage is in the focus of attention of obstetrician-gynecologists and pediatricians constantly. Endocrine, autoimmune, infectious factors threatened abortion are being studied. Sex hormone metabolism is important in maintaining and developing of pregnancy. It is believed that progesterone deficiency is one of the main causes of abortion in the first trimester [10, 11]. Despite successes in the study of etiology, pathogenesis, and the development of various 
methods for diagnosing and treating the threatened interruption of pregnancy, the frequency of miscarriages remains stable [12 - 14].

The number of studies studying the psychoemotional state of pregnant women with threatened abortion has been increasing in recent years. However, the issues of the prevalence and severity of manifestations of anxiety and the hormonal profile of pregnant women living in the armed conflict area are not insufficiently described.

The aim of the study was to identify the prevalence and severity of anxiety, the hormonal profile of in pregnant women with threatened interruption of pregnancy in the I and II trimesters, living in the Lugansk region in the area of armed conflict in Eastern Ukraine, to improve treatment and prophylactic measures and prevent obstetric and perinatal complications in such women.

Material and Methods. The study included 67 pregnant women who were hospitalized regarding TIP in I and II trimesters to the hospitals, located in the Lugansk region (group I). The control group consisted of 30 pregnant women with non-complicated obstetric anamnesis and physiological course of pregnancy with similar gestational period of pregnancy and place of residence (group II). Before the start of the examination, each woman signed an Informed Consent of the patient to conduct diagnostics, treatment and processing of personal data. The studies were conducted in compliance with the basic bioethical norms and the requirements of the Helsinki Declaration.

The criteria for inclusion in the main group were the woman's voluntary informed consent, the presence of symptoms of threatened abortion, I and II trimester of pregnancy.

Comprehensive clinical and obstetric examination in accordance to the current orders of the Ministry of Health of Ukraine was carried out. General clinical studies (blood group and $\mathrm{Rh}$ factor, general blood and urine tests, biochemical blood tests, coagulogram, colpocytology, $\mathrm{pH}$ determination and microscopic examination of the vaginal content), the concentrations of estradiol, progesterone, prolactin, cortisol, sex hormone binding globulin (SHBG) were carried out.

Spielberger State-Trait Anxiety Inventory (STAI) was used to assess the level of anxiety. This inventory is made up of 20 items for assessing trait anxiety (TA) and 20 for state anxiety (SA). A result of less than 30 points measures to a low level of anxiety, 31-44 points - to an average level and more than 45 points - to a high level of anxiety [15].

Statistical data processing was performed using SPSS 17.0 and Microsoft Excel for Windows (2013). The Shapiro-Wilk test was used to verify the normality of the data. Significant differences were estimated using the non-parametric Mann-Whitney test for 
independent samples, Spearman rank correlation analysis was used. The critical level of significance in testing statistical hypotheses was taken equal to 0.05 .

Results and Discussion. The average age of women in group I was Me (Q1-Q3) = 26.50 (22.00-32.50), in group II - 25.00 (21.00-30.75) years. The largest number of patients was observed at the age of 20-30 years (58 (67.44\%) and 25 (78.13\%), respectively), that is, among the active and employable part of the population. The average age of menarche in group I was 13.00 (12.00-14.00), in group II - 13.00 (12.00-14.00) years.

The first pregnancy was in $33(49.25 \%)$ women of group I and in $16(53.33 \%)$ - of group II. A history of childbirth was in 29 (43.28\%) and 12 (40.00\%), artificial abortions in $13(19.40 \%)$ and $7(23.33 \%)$, spontaneous abortions in $9(13.43 \%)$ and $3(10.00 \%)$, missed pregnancy - in $8(11.94 \%)$ and $2(6.67 \%)$, respectively.

In group I a history of cervical pseudo-erosion was in 16 (23.88\%), salpingoophoritis in $12(17.91 \%)$ women, and in group II in 5 (16.67\%) and 7 (23.33\%), respectively. Patients of group I had significantly higher levels of state and trait anxiety, it can be regarded as mental manifestations of a stressful state (table 1).

Table 1

Patients Psychometric profile (Me (Q1-Q3)

\begin{tabular}{|l|c|c|}
\hline & $\begin{array}{c}\text { Group I } \\
(\mathbf{n = 6 7})\end{array}$ & $\begin{array}{c}\text { Group II } \\
(\mathbf{n = 3 0})\end{array}$ \\
\hline State anxiety, point & $46,50(37,75-49,00) *$ & $28,50(25,00-31,50)$ \\
\hline Trait anxiety, point & $44,50(40,00-47,50) *$ & $30,50(26,75-30,00)$ \\
\hline
\end{tabular}

Note: $*-p<0,01$ between groups.

Low levels of SA were in 24 (35.82\%), moderate in $31(46.27 \%)$, high in $12(17.91 \%)$ women of group I, in group II - in 22 (73.33\%), 6 (20.00\%), and 2 (6.67\%), respectively. Low TA occurred in 21 (31.34\%), moderate in 35 (52.24\%) and high in 11 (16.42\%) pregnant women of group I, in group II - in 21 (70.00\%)), 7 (23.33\%) and 2 (6.67\%), respectively (Fig. $1)$. 


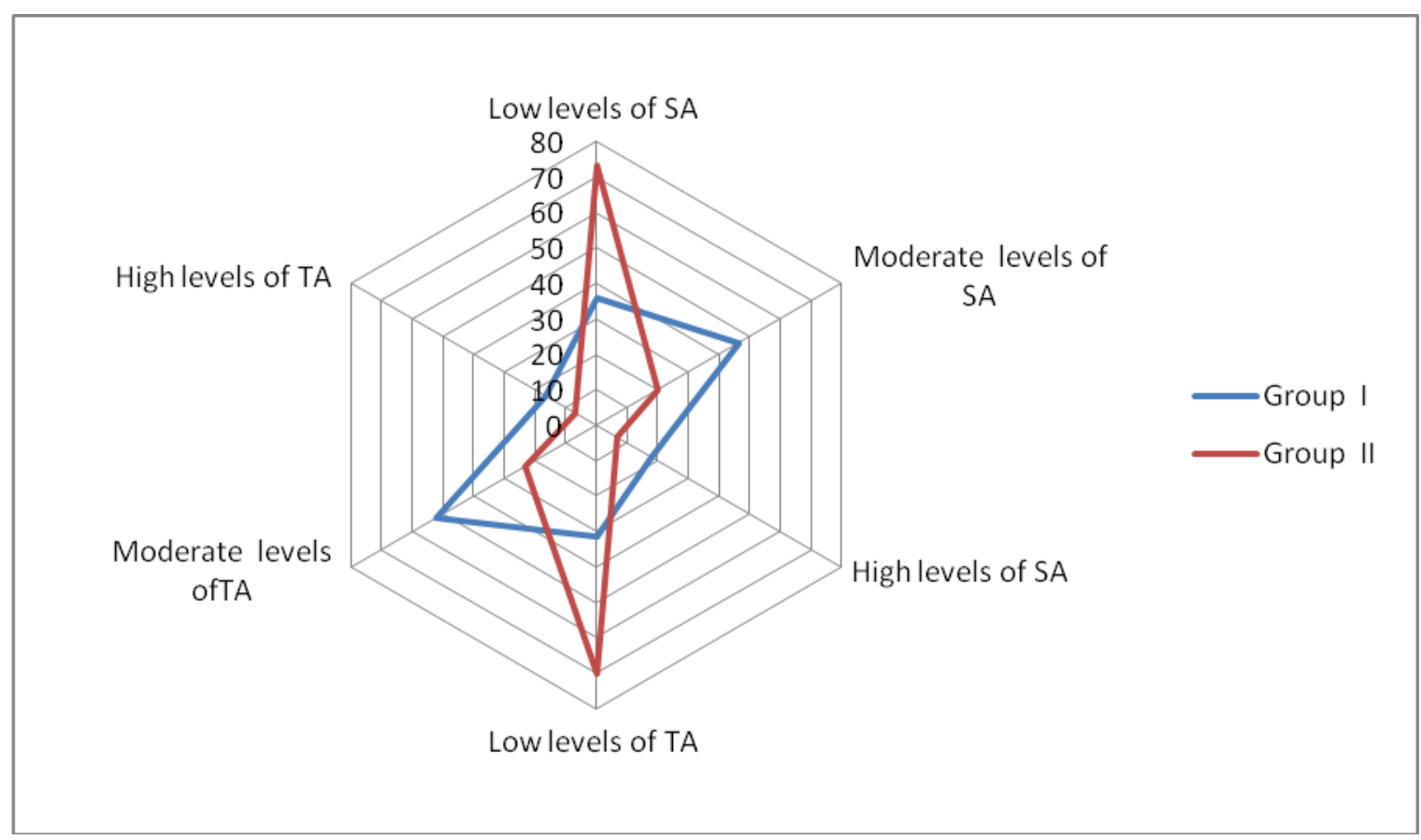

Fig. 1. The severity of SA and TA in the compared groups (in \%)

In group I, a tendency to relative hypoprogesteronemia was detected $(\mathrm{p}=0.064)$, excess levels of prolactin and cortisol were recorded (table 2).

Table 2

Indicators of hormonal homeostasis in the examined pregnant women (Me (Q1-Q3)

\begin{tabular}{|l|c|c|}
\hline \multicolumn{1}{|c|}{ Indicator } & \multicolumn{1}{c|}{$\begin{array}{c}\text { Group I } \\
(\mathbf{n = 2 8})\end{array}$} & $\begin{array}{c}\text { Group II } \\
(\mathbf{n = 2 0})\end{array}$ \\
\hline Progesterone (ng / ml) & $74,19(66,91-91,14)$ & $86,64(78,12-94,68)$ \\
\hline Prolactin $(\mathrm{ng} / \mathrm{ml})$ & $251,36(233,43-292,14)^{*}$ & $131,22(116,56-147,42)$ \\
\hline Cortisol $(\mathrm{ng} / \mathrm{ml})$ & $219,12(201,16-248,71)^{*}$ & $148,51(124,89-159,93)$ \\
\hline $\begin{array}{l}\text { Sex hormone binding } \\
\text { globulin (nmol / l) }\end{array}$ & $247,25(138,18-281,14)$ & $261,36(164,78-301,12)$ \\
\hline
\end{tabular}

Note: ${ }^{*}-\mathrm{p}<0,05$ between groups.

In our study, the average progesterone levels were within the gestational norm, however, it is necessary to note the presence of relative progesterone deficiency, which is clinically manifested by the manifestation of signs of threatening abortion.

In group I, a statistically significant correlations between the SA index and the concentration of cortisol $(r=0.538, p=0.004)$, prolactin $(r=0.468, p=0.037)$ were found.

In our study, the prevalence of anxiety among pregnant women with TIP slightly exceeds the data presented by Faisal-Cury A. and Rossi Menezes P. (59.5\%) [16], and amounts to $64.18 \%$. 
We found that patients with TIP were characterized by significantly higher rates of state and trait anxiety, it can be regarded as mental manifestations of a stressful state. In pregnant women of group I, the course of pregnancy is accompanied by a statistically significant excess of the concentration of cortisol, prolactin, and relative progesterone deficiency, which coincides with the data of Ku et al. [17].

\section{Conclusion}

The prevalence of TTH among pregnant women with TIP occurs in 1.92, migraines - 1.12 times more often than healthy pregnant women and made up $28.57 \%$ and $4.76 \%$, respectively. In pregnant women with TIP, according to VAS the intensity of TTH was 1.66, migraine was 1.25 times more higher than the data of the control group, the median value of TTH was significantly higher.

The prevalence of anxiety disorders among pregnant women with TIP living in the armed conflict area occurs in 2.4 times more often than healthy pregnant women and amounts to $64.18 \%$. Patients of group I had significantly higher levels of state and trait anxiety, there are positive correlations between the SA index and the concentration of cortisol and prolactin.

Antenatal study of levels of anxiety, hormonal homeostasis in pregnant women with threatened interruption of pregnancy living in the armed conflict area allowed to individualize the approach to the management of pregnancy and if needed to timely develop rehabilitating activities, that will contribute to a successful outcome of the pregnancy and affect the health of the mother and her offspring.

\section{Refences}

1. Keren M., Keren N., Eden A. et al. The complex impact of five years of stress related to life-threatening events on pregnancy outcomes: a preliminary retrospective study. Eur Psychiatry. 2015 Feb;30(2):317-21. doi: 10.1016/j.eurpsy.2014.10.004.

2. Biaggi A., Conroy S., Pawlby S. et al. Identifying the women at risk of antenatal anxiety and depression: A systematic review. J Affect Disord. 2016 Feb;191:62-77. doi: 10.1016/j.jad.2015.11.014.

3. Makhashvili N., Chikovani I., McKee M. et al. Mental disorders and their association with disability among internally displaced persons and returnees in Georgia. $\mathbf{J}$ Trauma Stress, 2014 Oct;27(5):509-18. doi: 10.1002/jts.21949.

4. King NM, Chambers J, O'Donnell K et al. Anxiety, depression and saliva cortisol in women with a medical disorder during pregnancy. Arch Womens Ment Health. 2010 Aug;13(4):339-45. doi: 10.1007/s00737-009-0139-5. 
5. Kicia M., Skurzak A., Wiktor K. et al. Anxiety and stress in miscarriage. Pol J Public Health. 2015;125(3): 162-165. doi: https://doi.org/10.1515/pjph-2015-0046.

6. Niloufer S. Ali, Iqbal S. Azam, Badar S. Ali et al. Frequency and Associated Factors for Anxiety and Depression in Pregnant Women: A Hospital-Based Cross-Sectional Study. Scientific World Journal. 2012; 2012: 653098. doi: 10.1100/2012/653098.

7. Rallis S., Skouteris H., McCabe M. et al. A prospective examination of depression, anxiety and stress throughout pregnancy. Women Birth, 2014 Dec;27(4):e36-42. doi: 10.1016/j.wombi.2014.08.002.

8. Lee A.M., Lam S.K., Sze Mun Lau S.M. et al. Prevalence, course, and risk factors for antenatal anxiety and depression. Obstet Gynecol, 2007 Nov;110(5):1102-12. doi: 10,1097 / 01.AOG.0000287065.59491.70.

9. Ahmed S.R., El-Sammani Mel-K., Al-Sheeha M.A. et al. Pregnancy outcome in women with threatened miscarriage: a year study. Mater Sociomed. 2012;24(1):26-8. doi: $10.5455 / \mathrm{msm} .2012 .24 .26-28$.

10. Evrenos A.N., Cakir Gungor A.N., Gulerman C. et al. Obstetric outcomes of patients with abortus imminens in the first trimester. Arch Gynecol Obstet. 2014;289:499504. doi: 10,1007 / s00404-013-2979-5

11. Shah D., Nagarajan N.. Luteal insufficiency in first trimester. Indian J Endocrinol Metab. 2013;17:44-49. doi: 10.4103/2230-8210.107834.

12. Parker V.J., Douglas A.J. Stress in early pregnancy: maternal neuro-endocrineimmune responses and effects. J Reprod Immunol. 2010;85:86-92. doi: 10.1016 / j.jri.2009.10.011.

13. Weiss J.L., Malone F.D., Vidaver J. et al. Threatened abortion: A risk factor for poor pregnancy outcome, a population-based screening study. Am J Obstet Gynecol. 2004;190:745-50. doi: 10.1016 / j.ajog.2003.09.023

14. Dadkhah F., Kashanian M., Eliasi G. A comparison between the pregnancy outcome in women both with or without threatened abortion. Early Hum Dev. 2010;86:19396. doi: 10.1016 / j.earlhumdev.2010.02.005.

15. Hanin Yu.L. Issledovanie trevogi v sporte. [Study of anxiety in sports]. Vopr. Psihologii. 1975;6:72-75

16. Faisal-Cury A., Rossi Menezes P. Prevalence of anxiety and depression during pregnancy in a private setting sample. Archives of Women's Mental Health. 2007;10(1):2532. doi: 10,1007 / s00737-006-0164-6. 
17. $\mathrm{Ku} \mathrm{C}$., Allen Jr. JC., Lek S. et al. Serum progesterone distribution in normal pregnancies compared to pregnancies complicated by threatened miscarriage from 5 to 13 weeks gestation: a prospective cohort study. BMC Pregnancy Childbirth. 2018;18,360. doi: 10,1186 / s12884-018-2002-z. 